AperTO - Archivio Istituzionale Open Access dell'Università di Torino

\title{
C. I. Lewis, Kant, and the reflective method of philosophy
}

\section{This is the author's manuscript}

Original Citation:

Availability:

This version is available http://hdl.handle.net/2318/1716119

since 2020-04-18T16:55:27Z

Published version:

DOI:10.1080/09608788.2018.1437538

Terms of use:

Open Access

Anyone can freely access the full text of works made available as "Open Access". Works made available under a Creative Commons license can be used according to the terms and conditions of said license. Use of all other works requires consent of the right holder (author or publisher) if not exempted from copyright protection by the applicable law. 


\title{
C. I. Lewis, Kant, and the Reflective Method of Philosophy
}

\author{
Gabriele Gava
}

\begin{abstract}
If it seems unquestionable that C. I. Lewis is a Kantian in important respects, it is more difficult to determine what, if anything, is original about his Kantianism. For it might be argued that Lewis's Kantianism simply reflects an approach to the a priori which was very common in the first half of the $20^{\text {th }}$ century, namely, the effort to make the a priori relative. In this paper, I will argue that Lewis's Kantianism does present original features. The latter can be detected by focusing on Lewis's account of the method of philosophy in the first chapter of Mind and the World Order (1929). In that context, Lewis argues that the method of philosophy should be reflective and critical. It will be my contention that this understanding of philosophy involves a therapeutic perspective, which bears important resemblances to Kant's account of transcendental reflection in the Amphiboly of the Critique of Pure Reason. I will illustrate how this therapeutic application of reflection works in Lewis's metaphysics. In this context, reflection can correct errors of reasoning that occur when we are operating within a particular conceptual scheme and use the criteria of reality that are appropriate in another.
\end{abstract}

\section{Introduction}

Among the classical pragmatists, it is probably in C. I. Lewis that we find the most evident ties with Kant's thought. ${ }^{1}$ This fact is acknowledged by Lewis himself when, in the context of an autobiographical sketch, he notices that: "the evidence of Kant in my thinking [...] is unmistakable" (Lewis 1970: 3-4). Lewis's Kantianism has been accordingly emphasized by various scholars. However, if it seems unquestionable that Lewis is a Kantian in important respects, it is more difficult to determine what, if anything, is original about his Kantianism. For it might be argued that Lewis's Kantianism simply reflects an approach to the a priori which was very common in the first half of the $20^{\text {th }}$ century, namely, the effort to make the a priori relative. While this approach argues that certain elements of our knowledge are a priori because they are not inductively derived from experience, it maintains that these elements cannot be considered to hold necessarily irrespective of contexts and historical perspectives. Different versions of this approach can arguably

\footnotetext{
${ }^{1}$ Interpreters who have emphasized Lewis's Kantianism are for example: Murphey 2005; Rosenthal 2007; Richardson 2007; Calcaterra 2015; O'Shea 2016; Heney 2017. In saying that it is in Lewis that we find the most evident ties with Kant, I do not want to suggest that there are not good reasons to see other pragmatists, as for example Charles S. Peirce or Josiah Royce, as much Kantian as Lewis. In fact, I have insisted on Peirce's Kantianism myself (cf. Gava 2008; Gava 2011a; Gava 2011b; Gava 2014a; Gava 2014b). What I mean is that it is less controversial to claim that Lewis is a Kantian, while there are many Peirce or Royce scholars who would maintain that these pragmatists are better described as Hegelians.
} 
be found in Poincaré's conventions (cf. Poincaré 1902), Reichenbach's relative a priori (cf. Reichenbach 1920), Cassirer's interpretation of the theory of relativity (cf. Cassirer 1921), and Carnap's linguistic frameworks. ${ }^{2}$

If what is "Kantian" in Lewis's approach were simply expression of this widespread tendency to relativize the a priori, investigating Kant's legacy to him would not be particularly illuminating. Now, in discussions of Lewis's relation to Kant, what is often emphasized is his theory of the pragmatic a priori. The latter holds that even though we must assume some a priori principles in our knowledge, we are not required to accept a pre-determined set of a priori categories. Rather, we have a multiplicity of different conceptual schemes at our disposal and choose which one to apply on pragmatic grounds (cf. O'Shea 2006; Richardson 2007). ${ }^{3}$ While this aspect of Lewis's appropriation of Kant can be associated to many of his contemporaries, I will here take the logical empiricists, and more precisely Carnap, as an example of this approach. Interpreters who read logical empiricism within a Kantian framework often underline views that are very close to Lewis's pragmatic a priori (cf. Friedman 1999, 2001; O’Shea 2006; Mormann 2012). But this seems a confirmation that Lewis's Kantianism does not single out any original aspect of his thought.

In this paper, I will argue that Lewis's Kantianism does present original features. The latter can be detected by focusing on Lewis's account of the method of philosophy in the first chapter of Mind and the World Order (1929). In that context, Lewis argues that the method of philosophy should be reflective and critical. It will be my contention that this understanding of philosophy involves a therapeutic perspective, which bears important resemblances to Kant's account of transcendental reflection in the Amphiboly of the Critique of Pure Reason. This chapter of the first Critique is notoriously obscure. However, one of its chief ideas is that transcendental reflection is able to determine the "faculty" through which the objects of a particular concept are given to us. In doing so, it allows us to avoid errors and misunderstandings which result from treating some concepts as

\footnotetext{
${ }^{2}$ This list does not of course even pretend to be exhaustive and could be much longer (cf. Coffa 1991). It might be argued that it is in fact unclear whether the authors just mentioned can be considered as close as I suggest here. For example, it is not clear whether Cassirer's account of the a priori is relative (and constitutive) or absolute (and regulative), or a mixture of these (On this issue see Heis 2014). Moreover, Reichenbach explicitly criticized Poincaré's conventionalism in geometry, even though he later revised his position (on this matter see Friedman 1999: chs. 3-4). We do not need to deal with these interpretative questions here. What is at issue here is only whether the authors that are mentioned can be read as proposing a relative interpretation of the a priori (and this is at least plausible for Cassirer as well). Therefore, it is a secondary problem whether Poncaré and Reichenbach attribute a relative a priori status to the same principles.

${ }^{3}$ Another aspect of Lewis's thought that is read in a Kantian fashion is the often criticized distinction between what is "given" and what the mind contributes to experience (for a criticism of Lewis on the given see Hookway 2000. For a defence see Gowans 1984 and Misak 2013: 181-4. Sachs 2014: ch. 2 introduces a useful distinction between an epistemic and a semantic given in Lewis). In this respect, Lewis's position can be read as presenting a new version of Kant's distinction between the analytic and the synthetic (cf. Baldwin 2013). Even this aspect of Lewis's Kantianism is not original though, since a similar reinterpretation of the analytic and the synthetic can be attributed to other figures, for example in the early Vienna Circle.
} 
if they were concepts of objects given to us through a different faculty, thereby using those concepts under the wrong conditions of application. Even though Lewis abandons Kant's vocabulary of faculties, he seems to ascribe a similar role to philosophical reflection, where by means of reflection we should refer "the given experience to its proper category" (Lewis 1929: 11).

I will begin by briefly presenting Lewis's account of the pragmatic a priori and compare it to Carnap's account of linguistic frameworks in "Empiricisms, Semantics and Ontology." Their positions will be shown to be similar in important respects. I will then introduce, first, Kant's account of transcendental reflection and, second, Lewis's characterization of the reflective method of philosophy. I will highlight both similarities and differences. I will conclude by suggesting that Lewis's account of the method of philosophy, and of metaphysics in particular, shows that Strawson's distinction between a "descriptive" and a "revisionary" metaphysics does not constitute a dichotomy between incompatible approaches. Rather, in Lewis's account, metaphysics can consistently incorporate both descriptive and revisionary features.

\section{Lewis's Pragmatic A priori and Carnap's Frameworks}

Lewis's pragmatic theory of the a priori applies to different sub-disciplines of philosophy, among which logic, ethics and metaphysics figure prominently (cf. Lewis 1929: ch. 1). In what follows, I will focus on metaphysics in particular, because, as it will become clear in section 4 , it is in the context of Lewis's considerations on metaphysics that the original aspects of his Kantianism come to full light. ${ }^{4}$ In metaphysics, the a priori identifies those criteria which allow us to order and classify objects of experience and to tell apart what is real from what is unreal. According to Lewis, these criteria are conceptual in nature and cannot be accounted for as the result of inductive generalisations. For before we can identify general characteristics of the real through inductive generalisations, we need to have already criteria in place that tell us which experiences can be categorized as veridical, and thus as tracking reality (cf. Lewis 1929: 27-8). We cannot interrogate nature and experience without already having some of these criteria at hand, where this does not mean that the criteria are not revisable or that we cannot give them up if they proved unsatisfactory for our epistemic aims. Insofar as they are criteria to determine what is real, they function as a priori elements of our knowledge of reality. In Lewis's account, these a priori criteria are distinctive because they are: 1) analytic and definitory in nature, 2) relative, and 3) arbitrary and selected on pragmatic grounds.

\footnotetext{
${ }^{4}$ Of course, I do not want to suggest that Lewis has not made important contributions to others fields of philosophy. He is know for his work on logic and epistemology. Moreover, Diana Heney (2017) has recently argued that Lewis's ethics deserves close attention as well. Furthermore, I believe that the therapeutic application of reflection that I will discuss in section 4 need not be restricted to metaphysics. I focus on this discipline only because it is in this context that Lewis is more explicit about the therapeutic potential of reflection.
} 
1. Analytic and definitory in nature. Even though categorial criteria determine our interpretation of what is real, they cannot be taken as synthetic a priori principles, that is, as principles that go beyond what is analytically entailed in a given conceptual scheme and are directly constitutive of experiences as such. Rather, these criteria are fundamentally definitory in character. They establish a category of the real by determining what fall under it by definition (cf. Lewis 1929: 239-40). Categories do not however come in isolation. They rather form complex conceptual schemes, where the relationships among different categories are articulated in a systematic way by relations of (sometimes mutual) entailment (cf. Lewis 1929: 79-83). Since the characters that are attributed to a determinate class of realities are ascribed to it by definition, this ascription cannot be proved wrong by experience: "If experience were other than it is, the definition and its corresponding classification might be inconvenient, useless, or fantastic, but it could not be false" (Lewis 1929: 240). To illustrate this feature of our a priori categorial structures, Lewis gives the example of our concept of a physical object (cf. 1929: 26-7). According to this concept, Lewis contends, it is true by definition that physical objects have mass. Since any experience that contrasted with this latter proposition would be classified as non-veridical, it cannot be proven wrong. This does not mean however that we cannot be in a position where a change in our definition of a physical object would be desirable. Given our usual experience of physical objects, we might find out that a different definition worked better. Moreover, if our experience were relevantly different, our current definition might prove useless (cf. 1929: 27). However, according to Lewis, it would be misleading to describe a change in our definition of a physical object by saying that a previous definition was "wrong" or "false." What are at issue instead are different ways of conceptualizing the world, where the only thing we can say is that we would be better off with one of these categorizations.

2. Relative. The physical object example points toward two further aspects of Lewis's approach to the a priori. Firstly, given that we might find out that a different definition of a physical object might be better suited to our purposes, a priori concepts cannot be taken to be absolutely valid. Rather, we are always in a position to find alternatives to our categorial schemes (cf. Lewis 1929: 232). This relative nature of the a priori is closely linked to its analytic structure. This is due to the fact that the a priori only determines relationships among concepts. We can have different ways of establishing these relationships and none of these necessarily constrains how we should experience things. "[T] he a priori is independent of experience, not because it prescribes a form which experience must fit or anticipates some pre-established harmony of the given with the categories of the mind, but precisely because it prescribes nothing to the content of experience. That only can be a priori which is true no matter what" (Lewis 1929: 197; cf. Lewis 1929: 232-3). 
3. Arbitrary and selected on pragmatic grounds. The second aspect that is alluded to in the physical object example is the arbitrary character of our categorial schemes. If we can opt for different definitions of physical objects, it means that it is open to our choice which categorial scheme we should adopt: "The a priori represents an attitude in some sense freely taken [my emphasis], a stipulation of the mind itself, and a stipulation which might be made in some other way if it suited our bent or need" (Lewis 1970: 231; cf. Lewis 1929: 196-7). But if we are free to choose among competing categorial schemes, according to which standards do we make a choice? Not surprisingly, Lewis's answer is that we operate the choice on pragmatic grounds. He seems to have a quite broad understanding of what can count as a pragmatic ground. The latter can be the expression of needs and interests common to the human species (cf. Lewis 1929: 239), or simply respond to heuristic criteria of simplicity and completeness in science (cf. 1970: 238). Here a qualification is in order: the fact that the selection of a categorial scheme is arbitrary and subject to pragmatic criteria of choice does not mean that this selection is ultimately based on subjective preferences. First, categorical schemes respond to internal criteria of consistency and to external criteria of aptness that cannot but be intersubjectively determined (cf. Lewis 1929: 237-9). Secondly, and most importantly, the establishment of a categorial scheme is essentially a social affair (cf. Lewis 1929: 111-16) and one in which the "choices" are the result of complex processes which are often not completely clear to the individual agents involved (accordingly, an individual can lack a clear grasp of the grounds of her choice, cf. Lewis 1929: 300).

If we now turn our attention to Carnap's late position and to his account of linguistic frameworks, his views seem similar to Lewis's in important respects. In "Empiricism, Semantics and Ontology" (Carnap 1950), Carnap uses the notion of a linguistic framework to distinguish between what he calls internal and external questions. ${ }^{5}$ External questions concern the suitability of a linguistic framework as a whole, whereas internal questions are those that are asked once we already operate within one. But what is a linguistic framework for Carnap? It identifies the set of statements, questions, and objects that can be considered legitimate on the basis of some rules and standards that are constitutive of a framework. Constitutive rules and standards can comprise syntactic and semantic rules of a language, ${ }^{6}$ meaning postulates (as the one stipulating that bachelor and married are incompatible properties, cf. Carnap 1952), but also, as in the case of physics, physical laws that are fundamental for a particular science (as for example the laws of motion in Newtonian physics, cf. Friedman 2001: 76-7; Uebel 2012: 14).

Carnap uses the concept of linguistic framework first of all to address questions of ontology. His purpose in this respect is twofold: on the one hand, he wants to show that an empiricist

\footnotetext{
${ }^{5}$ On the distinction between internal and external questions in Carnap see Bird 2003a.

${ }^{6}$ The focus on syntactic rules is central in Carnap 1934, whereas a semantic approach is displayed in Carnap 1956.
} 
philosophy does not necessarily need to endorse a nominalist position and deny the existence of abstract entities; on the other, he argues that the question of existence for these abstract entities makes only sense within the linguistic framework of which they are part. Let me illustrate this point with an example. One such linguistic framework that Carnap takes into account is the "thing language" of everyday language, which consists of "the spatio-temporally ordered system of observable things and events" (Carnap 1950: 206-7). The thing language contains expressions for properties like "red," "hard," etc. (Carnap 1950: 211). The question whether such properties exist is a question internal to the thing language and is a matter of empirical evidence. The empiricists should have no problem in accepting the existence of properties as an issue internal to the thing language. However, the question concerning the existence of properties can be also understood as an external question, that is, as a metaphysical question that asks whether there are "really" such things as properties in the world, independently of any conceptual framework in which we might be allowed to refer to such things. Carnap argues that, understood in such a way, the question concerning the reality of properties makes no sense: "the external statement $[\ldots]$ is devoid of cognitive content" (Carnap 1950: 212).

The only way in which the external question concerning the reality of properties can meaningfully be asked is when it is understood as a question regarding whether we should adopt the linguistic framework of which properties are part. As such, however, the question is not a theoretical question about what objects there is, but it is a practical question about what language is better for us to adopt. In this respect, we can have a multiplicity of languages, with different standards for the kind of ontological commitments that are permitted. Which of these languages we should adopt is a matter of choice, which can be based on a variety of pragmatic grounds (cf. Carnap 1950: 207).

How is Carnap's account of linguistic frameworks related to Lewis's pragmatic a priori? What are the implications for their respective Kantianism? In general, Carnap's position also seems to imply a form of Kantianism, since the rules and standards which constitute a framework have a sort of a priori validity, even if it is a relative one. The analogy with Lewis, however, is even deeper if we take into account the three aspects of Lewis's pragmatic a priori we just discussed. First, the set of rules and standards that are constitutive of a framework are for Carnap essentially conventional and stipulatory, where this claim brings him close to Lewis's contention that the a priori is definitory. As we saw, the standards and rules of a framework comprise syntactic and semantic rules, meaning postulates, and, sometimes, fundamental physical laws. Now, all these elements are conventional for Carnap. It is an open question, however, whether all of them can be considered analytic, as Lewis maintains for a priori categories, or whether some should be rather characterized 
as synthetic a priori (cf. Uebel 2012). This is particularly true for the physical laws that are sometimes constitutive of a framework. For our purposes, it is sufficient to note that a considerable set of these conventional rules, that is, syntactic and semantic rules, just as meaning postulates, are analytic. Moreover, there is a well established interpretative tradition which regards physical laws that are constitutive of a framework as analytic according to Carnap (cf. Friedman 1999: 85-6; Baldwin 2013: 210; Goldber 2015: 149). Thus, according to this latter approach, there is indeed an important convergence between him and Lewis as far as the characterization of standards and rules that are constitutive of a categorial scheme/linguistic framework are concerned. For both philosophers, these rules and standards are analytic and definitory/conventional in nature. But this is not all. We can draw similar conclusions if we take into consideration the two further aspects of Lewis's approach I analysed above. Like Lewis, Carnap maintains both that the validity of linguistic frameworks is relative (we can have a multiplicity of competing and incompatible frameworks) and that our choice to adopt one such framework is arbitrary and based on pragmatic grounds.

This is of course not meant to deny that there are significant differences between Lewis and Carnap. ${ }^{7}$ First of all, Carnap's frameworks are linguistic and identify different languages, whereas Lewis's approach is conceptual and focuses on alternative conceptual schemes. But this is of course what is already evident on the surface. In fact, there is an urgent need to adequately sort out the differences between Lewis and Carnap. Even though they engaged in a direct discussion regarding the relationships between their positions (cf. Lewis 1970: part 1, ch. 9; part 3, ch. 3; Carnap 1936/1937), it is in fact unclear how this exchange should be read. For example, while some scholars have followed Lewis's own criticisms of Carnap in their estimation of the relationship between the two (cf. Richardson 2007: 308-10), others have instead argued that Lewis's criticisms are only directed to Carnap's early views, while Carnap in the 1930s moved to a position much closer to Lewis's, independently of those criticisms (cf. Limbeck-Lilienau 2012). ${ }^{8}$ These interpretative issues are important, ${ }^{9}$ but they do not need to concern us here. For what is at issue is not a comprehensive comparison between Lewis and Carnap, but rather the question whether Lewis's Kantianism can be seen as original in comparison with Carnap's. As far as the Kantian

\footnotetext{
${ }^{7}$ For example, Olen (2017) insists on important differences between their accounts of verification.

${ }^{8}$ For an assessment of Lewis's criticism of Carnap and of logical positivism more generally see also Murphey 2005: ch. 7.

${ }^{9}$ While I side with those interpreters that attribute a sort of pragmatism to the late Carnap, also this issue is in fact unsettled. While many interpreters see the mature Carnap in a pragmatist light (cf. Richardson 2007; Misak 2013: 1735), others have recently claimed that Lewis's position on the a priori is original with respect to Carnap's because Carnap has a purely theoretical account of scientific knowledge which neglects practical aspects (cf. Mormann 2012).
} 
nature of their thought is concerned, ${ }^{10}$ there is convergence among interpreters in emphasizing exactly those features of their account of the a priori which we have pointed out (cf. Friedman 1999, 2000; O'Shea 2006; Baldwin 2013). ${ }^{11}$ But this seems to confirm our worry that Lewis's Kantianism does not single out any original element of his thought. In the next sections, I will argue that Lewis's Kantianism is in fact original and that this originality becomes apparent if we compare Lewis's reflective account of the method of philosophy to Kant's views on the role of transcendental reflection.

\section{Kant's Account of Transcendental Reflection}

In this section, I will clarify the way in which for Kant transcendental reflection exerts a sort of therapeutic function with respect to our reasoning. The fact that there is a therapeutic concern at the centre of the Critique of Pure Reason can hardly escape the eye of a careful reader. By therapeutic concern I mean the attempt to diagnose and correct errors in our reasoning that seem both to relate to objects that have a central importance for us as human beings and stem from the very form of our rationality. This perspective is essential in the Transcendental Dialectic of the first Critique and more precisely in Kant's account of transcendental illusion. ${ }^{12}$

However, the Transcendental Dialectic is not the only section of the Critique with a therapeutic standpoint. The Amphiboly of the Concepts of Reflection can also be read in this light, ${ }^{13}$ where the errors that it diagnoses are of a different kind. Although the Amphiboly is sometimes judged to be irrelevant for understanding both the first Critique and Kant's philosophy as a whole, ${ }^{14}$ some

\footnotetext{
${ }^{10}$ Still a further issue is whether Lewis's and Carnap's interpretations of Kant are correct. As far as Lewis is concerned, Kenneth Westphal (2010) and Jim O'Shea (2016) do a wonderful job in pointing out various infelicities in his reading of Kant.

${ }^{11}$ Mormann (2012) and Westphal (2017) constitute an exception. The former does not see Carnap's version of the a priori as pragmatic. The latter emphasizes a difference between the two when he argues that, unlike Carnap's relative a priori, Lewis's pragmatic a priori is “robustly realist." Besides, O'Shea (2016) emphasizes another aspect of Lewis's Kantianism that I haven't discussed here, that is, his insistence on the conceptual origin of modal constraints in the form of counterfactual sustaining causal laws. O'Shea claims that this approach puts Lewis's Kantianism in the tradition of Sellars and Brandom. Bird 2006 also emphasize the Kantian nature of Carnap's mature thought. However, he uses a somewhat different strategy with respect to mine. That is to say, he does not rely on Carnap's account of the a priori. Rather he draws a comparison between Carnap's distinction between internal and external questions and Kant's distinction between empirical and transcendental investigation (cf. 92-6). Having said that, I think his interpretation of Carnap's Kantianism fundamentally agrees with the one presented in this section.

${ }^{12}$ On Kant's theory of transcendental illusion see Grier 2001. On the therapeutic character of Kant's approach see Bird 2006: ch. 24.

${ }^{13}$ De Boer (2010) emphasizes the therapeutic aspect of the Amphiboly. Merritt's (2015) claim that transcendental refection should be read as a special applied logic can be also understood as emphasizing this therapeutic role. Heßbrüggen-Walter (2004) also presents a similar approach.

${ }^{14}$ Willaschek (1998: 341-2) suggests that, given the many similarities between the Amphiboly and Kant's Inaugural Dissertation, the discussion of transcendental reflection in the Critique of Pure Reason can be read as presenting a residuum of pre-critical doctrines, which do not fit very well in the critical system.
} 
authors have put it at the centre of their interpretation of the first Critique. ${ }^{15}$ When considering this section, interpreters often direct their attention either to the criticism of Leibniz it contains (cf. Parkinson 1981; Pereboom 1991), or to the role that logical and transcendental reflection play, respectively, in Kant's account of judgment and in the method of the Critique itself (cf.

Longuenesse 1998: chs. 5-6; Smit 1999), which means that the therapeutic concern of the Amphiboly often gets overlooked; or better, it is reduced to a critique of Leibniz's metaphysics. Therefore, my purpose in this section will be to throw light on this aspect of the Amphiboly.

According to Kant, transcendental reflection should provide a solution to "transcendental amphibolies," which he describes as errors of reflection. But what is reflection for Kant? Kant uses the term in a multiplicity of ways and it is not clear if these uses can be traced back to a common root. For example, La Rocca (1999: 148-54) identifies 5 different senses of reflection, whereas 6 varieties figure in Merritt's (2015: 479) account of the issue. For the purposes of this paper, I will limit my attention to the senses of reflection that are relevant in the Amphiboly. In this context, Kant distinguishes between logical and transcendental reflection. The former is a comparison among different concepts. Kant identifies four main respects according to which representations can be compared. Accordingly, logical reflection is guided by four couples of concepts, which Kant names concepts of reflection. We can compare our concepts with respect to their identity/difference, agreement/opposition, or also with respect to what is internal/external to them, or to what should count as form/matter (or, alternatively, determination/determinable) in them (cf. A 261/B 317; A 263-8/B 319-4). ${ }^{1617}$ Melissa Merritt has recently shown that Kant's account of logical reflection in the Amphiboly is very close to Georg Friedrich Meier's description of reflection in the Auszug aus der Vernunftlehre, a text which, as is well known, Kant used as a textbook for his lectures on logic. ${ }^{18}$ According to her interpretation, logical reflection, in both Kant and Meier, "is trained on concepts that are already in hand - and not obviously to create new ones, but rather to clarify existing concepts and their relation in an organized whole" (Merritt 2015: 491). ${ }^{19}$ Logical reflection is thus an activity through which we analyse concepts we already have and organize them in hierarchical relationships of genera and species. For example, we can organize our concepts

\footnotetext{
${ }^{15}$ For example, Longuenesse (1998: ch. 6) has argued that the concepts of reflection are fundamental for a correct understanding of Kant's tables of judgments, whereas Leitner (1994) contends that the idea of a Transcendental Topic is a key to understanding Kant's method.

${ }^{16}$ References to the Critique of Pure Reason use A and B to refer respectively to the pagination of the first and the second original editions. For translations, I have used the Guyer/Wood edition (Kant 1998).

${ }^{17}$ For some useful examples illustrating how different judgments can result from the comparison of concepts carried out in accordance with different concepts of reflection see de Boer 2010: 62-3.

${ }^{18}$ Merritt contests Ginsborg's (2006) claim that logical reflection is an activity through which we can obtain concepts starting from non-conceptual representations, like intuitions.

${ }^{19}$ Even if I here follow Merritt's interpretation of logical reflection, the main point of this section, which concerns transcendental reflection, can in fact be made consistent with other accounts of logical reflection, like Longuenesse's (1998: chs. 5-6) and de Boer's (2010), who both see logical reflection in connection to the process of judging.
} 
"animal," "human," and "horse" by characterizing "animal" as superordinate with respect to the other two because it is constituted by "marks" that "human" and "horse" have in common, while "human" and "horse" have also additional marks that determine their specific differences. ${ }^{20}$

I will now focus on two aspects of logical reflection which are important for understanding what transcendental reflection is. First, logical reflection focuses only on the representational content of concepts, without inquiring if they actually refer to objects. Secondly, it avoids considering the cognitive faculty through which the objects of these concepts are given to us (cf. A 262/B 318; A 269-70/B 325-6). Even if in logical reflection we compare concepts, this does not mean that the objects of those concepts are originally given to us through concepts. In fact, Kant holds that it is only through intuition that objects can be given to us. We can for now ignore this claim and simply keep in mind that logical reflection compares concepts without considering if the objects of those concepts are originally given to us either through concepts and pure thought or through intuition and sensibility.

According to the first aspect of logical reflection I just listed, as long as we logically reflect on two concepts, we do not consider them for their objective content, that is, we do not use the comparison to form judgments on objects. Therefore, the relations that are at stake in logical reflection are only relations among representations. The situation is different if we compare our concepts with the aim to cognize something about objects by means of this comparison. This is not any more only a logical comparison, but is an objective comparison (cf. A 263/B 319). For example, we can compare our concepts of "human" and "horse" in order to find common "marks" among them. We can then use these common marks to identify a superordinate concept that encloses them both, like the concept of a "mammal." As long as we treat all these concepts only as representations, we are still only logically reflecting on them. But as soon as our comparison results in a judgment on which objects there are, we perform an objective comparison, as when we say that mammals form a natural kind. It is when we reflect on representations in this way that we risk of falling into amphibolies. Kant accordingly maintains:

But if we would get to the objects with these concepts [that is, the concepts that are being compared, $m y$ note], then transcendental reflection about which cognitive power they are objects for, whether for the pure understanding or for sensibility, is necessary first of all. Without this reflection I can make only a very insecure use of these concepts, and there arise allegedly synthetic principles, which critical reason

\footnotetext{
${ }^{20}$ Longuenesse sometimes seems to have a similar understanding of logical reflection (cf. Longuenesse 1998: 11314n22). However, in contrast to Merritt, she tries to use Kant's account of logical reflection to illuminate both the process of judgment and the process through which empirical concepts are obtained from non-conceptual materials, two processes that she sees as fundamentally related (cf. Longuenesse 1998: 114-15).
} 
cannot acknowledge and that are grounded solely on a transcendental amphiboly, i.e., a confusion of the pure object of the understanding with the appearance. (A 269-70/B 325-6)

A transcendental amphiboly is then a "confusion of the pure object of the understanding with the appearance." What Kant has in mind in this respect seems to be connected to the second aspect of logical reflection I mentioned above: logical reflection avoids considering the cognitive faculty through which an object of representation is given to us. We have seen that neglecting this aspect is fine as long as we reflect only logically on concepts. However, when our comparison is used to judge on the objects that are represented, we face the risk of falling in an amphiboly. The risk rests on the fact that the conditions on our use of the concepts of reflection in objective comparisons are different for concepts of objects that are given to us respectively in intuition and pure thought:

But since, if it is not the logical form but the content of concepts that is concerned, [...] the things can have a twofold relation to our power of cognition, namely to sensibility and to understanding, yet it is this place in which they belong that concerns how they ought to belong to each other, then it is transcendental reflection, i.e., the relation of given representations to one or the other kind of cognition, that can alone determine their relation among themselves, and whether the things are identical or different, in agreement or in opposition, etc., cannot immediately be made out from the concepts themselves through mere comparison (comparatio), but rather only through the distinction of the kind of cognition to which they belong, by means of a transcendental reflection (reflexio). (A 262/B 318)

Therefore, the task of transcendental reflection is to make sure that the conditions for the correct use of the concepts of reflection for objective comparisons are met and to diagnose when errors occur because these conditions are not satisfied. Since the conditions for the correct use of concepts of reflection depend on the faculty through which the represented objects are given to us, transcendental reflection accomplishes its task by establishing if the objects of the compared concepts are given to us through intuition or pure thought.

Let me illustrate how an amphiboly can arise by taking into consideration Kant's criticisms of Leibniz' principle of the identity of indiscernibles (cf. A 263-4 /B 319-20; A 271-2 /B 327-8). As is well known, this principle says that two objects with identical properties must also be numerically identical. Kant suggests that the principle is flawed and that this flaw rests on an incorrect application of the concepts of reflection which establish relationships of identity and difference among representations and their objects. The conditions for the use of these concepts are different for concepts of objects given in intuition and objects given in pure thought. For concepts of objects given in pure thought, we would be able to cognize an object simply by means of its concept 
(something which is in fact impossible for us). A comparison between two concepts that established that their marks are identical would be sufficient to establish both the identity of the concepts and the numerical identity of their objects. By contrast, the identity of two concepts of objects is not sufficient to establish the numerical identity of the represented objects if the latter can only be given to us in intuition. This is the case because two perfectly identical sensible objects could still be numerically different if they occupy different places at the same time. Therefore, since in this case an identity in the properties of the objects is not sufficient to infer the numerical identity of the objects, it follows that an identity in the concepts of those objects cannot do the trick either.

To summarize, according to Kant's diagnosis of Leibniz's amphiboly regarding the identity of indiscernibles, Leibniz made one crucial mistake: he tried to determine the conditions for the identity of things by reflecting on concepts of objects, assuming that the objects of those concepts could be given to us through concepts and pure thought. In doing so, he failed to realize that the objects of those concepts could in fact only be given to us in intuitions (since this is the only way in which objects can be given to us), which implies that the conditions for determining their identity and difference through reflection are not those of objects of pure thought. It is this kind of mistake that transcendental reflection is designed to remedy. Transcendental reflection determines the conditions for correctly applying concepts of reflection in objective comparisons, that is, in comparisons that result in judgments on objects, by determining whether the objects of the compared concepts are given to us in intuitions or pure thought.

Let me conclude this section with a brief consideration. Leibniz is certainly the main critical target of the Amphiboly. However, the purpose of Kant's remarks on transcendental reflection is not exhausted by his critique of Leibniz. Leibniz only provides an example of the kind of errors into which we can fall when we objectively compare concepts without transcendentally reflecting on them. In the Amphiboly, Kant provides a diagnosis of the sources of Leibniz's mistakes which purports to be valid beyond Leibniz's particular arguments in favour of, say, the identity of indiscernibles. This diagnosis is meant to be valid for any objective comparison that fails to consider the faculty through which the objects of the compared concepts are given to us.

\section{Lewis on the Reflective Method of Philosophy}

What can Kant's account of transcendental reflection possibly have to do with Lewis's approach to the method of philosophy? In order to illustrate that Lewis's reflective account of philosophy does have something in common with the therapeutic task of transcendental reflection according to Kant, I will focus on Lewis's account of the method of philosophy in Mind and the World Order. I will first introduce the general reason why for Lewis philosophy needs to proceed reflectively. While in 
this general sense Lewis's reflective method seems indeed to be distant from Kant's idea of transcendental reflection, there is another specific task of reflection which has relevant therapeutic implications for Lewis. It is this therapeutic task of the method of philosophy that can be read in connection with the Amphiboly of the first Critique.

Let us first see what for Lewis the method of philosophy should not be. Philosophy should not proceed under the assumption that it can add new knowledge to the stock of our positive knowledge about reality: "It is not the business of philosophy, as it is of the natural sciences, to add to the sum total of phenomena with which men are acquainted" (Lewis 1929: 2). This does not however mean that there is no meaningful task left for philosophy and that all that was commonly done by philosophers is better left to scientists working in different fields. On the contrary, the task of philosophy is to clarify those fundamental categories and principles that we use when we interpret reality. These categories and criteria involve dichotomies such as right and wrong, valid and invalid, real and unreal, beautiful and ugly etc. (cf. Lewis 1929: 27). In clarifying these criteria, philosophy does not produce new knowledge, but instead "investigate what we already know" (Lewis 1929: 2). It "is concerned with what is already familiar" (Lewis 1929: 2-3). But if this is the task of philosophy, why do we need it after all? Lewis's answer is that the categories analysed by philosophy are known only implicitly and philosophy is able to make them explicit:

To know in the sense of familiarity and to comprehend in clear ideas are, of course, quite different matters. [...] If it were not for this, naïve common-sense and philosophy would coincide, and there would be no problem. Just this business of bringing to clear consciousness and expressing coherently the principles which are implicitly intended in our dealing with the familiar, is the distinctively philosophic enterprise. (Lewis 1929: 3)

According to its most basic sense, the claim that philosophy should proceed reflectively simply refers to the fact that, on the one hand, it should start from assuming both common-sense beliefs and beliefs that are uncontroversial in our scientific practices, and, on the other hand, it should engage in a sort of second order investigation of those beliefs in order to bring to clear light their conceptual structure. It is this second aspect which properly identifies the reflective nature of the method of philosophy. Its aim is to identify those concepts and principles which play a fundamental role in our conceptual schemes. As far as metaphysics is concerned, the task of philosophical reflection, in this basic sense, is that of making explicit our categories of reality, that is, those criteria that play a constitutive role in our interpretation of experience and that allow us to distinguish between what is real and what is unreal. These criteria are exactly those a priori 
principles which I discussed in section 2, where I considered Lewis's account of the pragmatic a priori.

Now, if the only task of philosophical reflection were clarificatory and descriptive in such a way, there would be little sense in comparing Lewis's idea of the method of philosophy with Kant's account of transcendental reflection. However, Lewis explicitly argues that the clarifications carried out by philosophical reflection have a critical potential. For even though philosophy simply makes principles which are implied in our systems of beliefs explicit, this does not mean that we always apply these implicit principles properly: "It is true in metaphysics, as it is in ethics and logic, that while valid principles must be supposed somehow implicit in the ordinary intercourse of mind with reality, they are not present in the sense of being fatally adhered to. If they were, the philosophic enterprise would have no practical value" (Lewis 1929: 18). It would be wrong to maintain that philosophy's method is only descriptive and clarificatory:

Philosophy cannot be merely a verbally more precise rendering of common-sense, nor a direct generalization from actual practice. Though it raises from what is implicit in experience, its procedure must be critical, not descriptive. So far as it is to be of use, it must assume the function of sharpening and correcting an interpretation which has already entered into the fabric of that experience which is its datum. Logical principles aim to replace the uncritical moral sense, ethics, our naïve morality, and metaphysics, our unreflective ontological judgments. (Lewis 1929: 19)

Thus, philosophical reflection does not only describe what is implicit in our ordinary and scientific beliefs, it also diagnoses and corrects the incorrect application of those principles which are made explicit in philosophical clarifications. This means that philosophical reflection has indeed therapeutic implications for Lewis.

But how does philosophical reflection perform its therapeutic task in metaphysics? There is probably a multiplicity of ways in which the clarifications carried out by philosophy can have therapeutic applications. If we give attention to Lewis's considerations concerning the ambiguity of the term reality, it seems that at least one of these ways bears some resemblance to the procedure envisioned by Kant's transcendental reflection. First of all, Lewis notices that "the adjective 'real' is systematically ambiguous and can have a single meaning only in a special sense" (Lewis 1929: 11). This means that the concepts of real and unreal have not an univocal application and cannot be used to draw a firm line between objects. Rather, the adjectives "real" and "unreal" make sense only in context, with reference to the conceptual scheme we are using to talk about reality in a particular occasion. What is unreal according to one conceptual scheme might be real with respect to another and there is nothing wrong about that: "A dream is illusory because the dreamer takes its 
images for physical things, but to the psychologist [...] just these experienced images [...] constitute a reality to be embraced under law and having its own indisputable place in the realm of fact" (Lewis 1929: 11-12). Therefore, Lewis is suggesting that the conditions for applying the concepts real and unreal are determined by the conceptual scheme we are using to judge the object in a particular case.

While these considerations might simply be taken as an invitation to clarify the sense in which we say a particular object is real, they are more than that. For there are cases in which applying certain criteria to judge if something is real or unreal is inadequate. For example, if we use the criteria belonging to the conceptual scheme of current physics in order to argue that everyday objects like chairs and tables are unreal, we apply those criteria in an inappropriate way. We do a similar mistake if we use those criteria to decide if moral reasons are real or not. In both these cases we are operating under a particular conceptual scheme, respectively, common sense and morality, but we use the concepts of the real and the unreal of another conceptual scheme, that is, current physics. The task of philosophical reflection is that "of determining the criteria by which the adjective 'real' is correctly applied" (Lewis 1929: 10). But since these criteria change according to the conceptual scheme we use to judge upon a particular object, this means that "the problem of distinguishing the real from unreal [...] is always a problem of right understanding, of referring the given experience to its proper category" (Lewis 1929, 11).

I think that the analogy with Kant's transcendental reflection can now be fully appreciated. As transcendental reflection was able to determine the conditions to correctly apply concepts of reflection by clarifying through which faculty the objects of the compared concepts are given to us, philosophical reflection is for Lewis capable of determining the conditions to correctly apply the concepts of real and unreal by making clear the conceptual scheme we use to judge on a given object, so that we can use the concepts of real and unreal under the conditions appropriate for that conceptual scheme. I am not denying that there are many differences between Kant's transcendental reflection and Lewis's reflective method. There are however interesting points of convergence. Both recognize that some concepts (concepts of reflection for Kant, the concepts of real and unreal for Lewis) have different conditions of applications in different domains. In Kant, the domains are, on the one hand, the domain of objects that are given to us through intuition and, on the other, the domain of objects that are given to us in pure thought. In Lewis, the domains reflect the various conceptual schemes we have, with their different ontological commitments. Both think that we can diagnose misuses of the concepts of, respectively, reflection and real and unreal by showing that we are using them for determining characteristics of objects in a particular domain applying the conditions that are appropriate in another domain. As we saw, Kant criticized the idea of the 
identity of indiscernibles because it rested on an application of the concepts of identity and difference under the conditions appropriate for the domain of objects that are given to us in pure though for objects that are in fact given to us in intuitions. In a similar way, according to Lewis's reflective method, we could criticize somebody that denies that moral obligations are real because she applies the concepts of real and unreal under the conditions appropriate for the domain of, say, current physics, for deciding which objects are real in the domain of morality.

We have already seen in section 2 that for Lewis we choose which conceptual scheme to use in a given context on pragmatic grounds. This is true both if we have to choose between competing conceptual schemes, as when we have two incompatible fundamental theories in physics, or between coexisting conceptual schemes, as when we use alternatively the conceptual scheme of current physics and the conceptual scheme of common sense. By contrast, the role of philosophical reflection is that of obtaining clarity over the different conceptual schemes we currently have and to correct errors of reasoning that occur when we are operating within a particular conceptual scheme and use the criteria of reality that are appropriate in another. In this way, philosophical reflection is able to correct misguided ontological commitments that depend on an erroneous application of the concepts of real and unreal.

\section{Conclusion: What Kind of Metaphysics for Lewis?}

In this paper I have suggested that Lewis's Kantianism can be considered original with respect to other forms of Kantianism of the first half of the $20^{\text {th }}$ century. ${ }^{21}$ This originality becomes apparent if one focuses on the therapeutic implications of Lewis's reflective method of philosophy. In this respect, one task of philosophical reflection in metaphysics is that of elucidating the conditions of application for the concepts of "real" and "unreal" by making clear which conceptual scheme we use to judge on a given object or phenomenon. I have maintained that this therapeutic task of philosophy can be seen as bearing a Kantian background, since it displays some similarities with Kant's account of transcendental reflection and of its role to solve amphibolies. ${ }^{22}$

\footnotetext{
${ }^{21}$ One interesting question here is whether the originality of Lewis's Kantianism might be accounted for when we see it as the culmination of a genuinely pragmatist appropriation of Kant. This would find support in Murphey's (2005) reading of Lewis, who sees him as developing the pragmatist Kantianism of Peirce and Royce. Yet the Kantianism displayed by Lewis's reflective method seems to introduce relevant elements of novelty, even in comparison with his pragmatist predecessors. That does not however rule out that it was their version of Kantianism that prepared the ground for the therapeutic aspects of Lewis's account of reflection.

${ }^{22}$ One could here object that a similar therapeutic function is also implicit in Carnap's idea of a linguistic framework, which would make Lewis's position not so original after all. It might be true that Carnap's theory of linguistic frameworks provides the means to achieve therapeutic results similar to those envisioned by Lewis's philosophical reflection. However, Carnap was not himself interested in such an application for his theory. Rather, the only therapeutic consequence that he conceived of was judging as devoid of meaning those external questions which ask whether some objects are real independently of any framework. He did not discuss the possibility of incorrectly applying criteria of a framework when using the language of a different framework.
} 
Let me here conclude with a broader consideration on Lewis's reflective method in metaphysics. What is interesting about it is that it not only displays something original about his Kantianism, but it also presents an innovative approach to metaphysics more broadly. We can appreciate this originality if we compare his understanding of the task and method of metaphysics with Strawson's famous distinction between a descriptive and a revisionary approach to this discipline. In Strawson's words, these two approaches can be characterized as follows:

"[d]escriptive metaphysics is content to describe the actual structure of our thought about the world, revisionary metaphysics is concerned to produce a better structure" (Strawson 1959: 9). Clearly, Lewis's reflective method does not fit properly in either one of these characterizations. On the one hand, it does begin from a consideration of the actual structure of our thought about the world as descriptive metaphysics does. Lewis accordingly maintains that philosophy is concerned with what is already familiar. But this does not mean that philosophy should not perform a therapeutic and corrective function with respect to our unreflective ontological commitments. We have seen that philosophy is not only descriptive, but also critical. ${ }^{23}$ It can point out that using the appropriate categories within a particular conceptual scheme requires us to change these commitments. The interesting point in this respect is that philosophy cannot perform this critical task properly without being also descriptive, without mapping the conceptual schemes we have at our disposal. Therefore, Lewis's reflective method appears to incorporate elements of both descriptive and revisionary metaphysics, without being reducible to either of them. In this way, it might not only display something original about his Kantianism, but also about his approach to metaphysics more broadly. $^{24}$

\section{References}

\footnotetext{
${ }^{23}$ Here, a possible objection could maintain that it is misleading to set Strawson's descriptive metaphysics in opposition to a therapeutic concern, since for Strawson descriptive metaphysics does have therapeutic applications against sceptical doubts. This is true, but it shows that Strawson's account of the descriptive approach is in fact vague, since it can be interpreted in two different ways: either as a purely descriptive method with no therapeutic application, or as a partially descriptive method with anti-sceptical applications. Alternatively, one could also point out that Strawson has indeed recognized a distinctively therapeutic kind of philosophy later in his career, where he used the images of the therapist and the grammarian to distinguish between two opposing understandings of analytic philosophy (cf. Strawson 1992: ch. 1). However, Strawson's therapist, who is exemplified by Wittgenstein, seems different from Lewis's "reflecting" philosopher for at least one reason. For Strawson, therapy can only have negative results. It can show that the use of some concepts and terms in a certain context is devoid of meaning. But this means that therapy cannot be of any help to metaphysics, whereas for Lewis critical consequences form an integral part of metaphysics. For some interesting considerations on the ambiguity of Strawson's distinction between descriptive and revisionary metaphysics see Bird 2003b, who concludes that Strawson's dichotomy should be rejected.

${ }^{24}$ I would like to thank Graham Bird, Karin de Boer, Melissa Merritt, Marcus Willaschek, two anonymous referees for the British Journal for the History of Philosophy and the audience of a conference in Milan for very useful feedback on earlier versions of this paper.
} 
Baldwin, T. (2013), “C. I. Lewis and the Analyticity Debate," in The Historical Turn in Analytic Philosophy, ed. by E. H. Reck, 201-27, Basingstoke: Palgrave Mcmillan.

Bird, G. (2003a), “Carnap's Internal and External Questions,” in Language, Truth and Knowledge: Contributions to the Philosophy of Rudolf Carnap, ed. by T. Bonk, 97-131, Dordrecht: Kluver.

Bird, G. (2003b), “Kant's and Strawson's Descriptive Metaphysics,” in Strawson and Kant, ed. by H-J. Glock, 67-85, Oxford: Oxford University Press.

Bird, G. (2006), The Revolutionary Kant: A Commentary to the Critique of Pure Reason, La Salle: Open Court.

de Boer, K. (2010), “Pure Reason's Enlightenment: Transcendental Reflection in Kant's First Critique," Kant Yearbook, 2: 53-74.

Calcaterra, R. (2015), “Categorical Ways of Acting. Remarks on C. I. Lewis's Amendment of Kantian a priori," European Journal of Pragmatism and American Philosophy, 7: 40-53.

Carnap, R. (1934), Logische Syntax der Sprache, Wien: Springer.

Carnap, R. (1936/1937), “Testability and Meaning,” Philosophy of Science, 3: 419-71, 4: 1-40.

Carnap, R. (1950), "Empiricism, Semantics and Ontology," in Revue Internationale de Philosophie 4: 20-40; reprinted in Carnap 1956, 205-21. Page references are given according to the reprinted edition.

Carnap, R. (1952), “Meaning Postulates,” Philosophical Studies, 3: 65-73; reprinted in Carnap $1956,222-9$.

Carnap R. (1956), Meaning and Necessity, enlarged edition, Chicago: University of Chicago Press, 1956.

Cassirer, E. (1921), Zur Einsteinschen Relativitätstheorie. Erkenntnistheoretische Betrachtungen, Berlin: Bruno Cassirer. 
Coffa, A. (1991), The Semantic Tradition from Kant to Carnap: To the Vienna Station, Cambridge: Cambridge University Press.

Friedman, M. (1999), Reconsidering Logical Positivism, Cambridge: Cambridge University Press.

Friedman, M. (2001), Dynamics of Reason, Stanford: CSLI Publications.

Gava, G. (2008), “The Purposefulness in our Thought: A Kantian Aid to Understanding some Essential Features of Peirce," Transactions of the Charles S. Peirce Society, 44: 699-727.

Gava, G. (2011a), “Does Peirce Reject Transcendental Philosophy?” Archiv für Geschichte der Philosophie, 93: 195-221.

Gava, G. (2011b), “Peirce’s 'Prescision' as a Transcendental Method,” International Journal of Philosophical Studies, 19: 231-53.

Gava, G. (2014a), Peirce's Account of Purposefulness: A Kantian Perspective, London \& New York: Routledge.

Gava, G. (2014b), "What is Wrong with Intuitions? An Assessment of a Peircean Criticism of Kant," Transactions of the Charles S. Peirce Society, 50: 340-59.

Ginsborg, H. (2006), "Thinking the Particular as Contained under the Universal," in Aesthetics and Cognition in Kant's Critical Philosophy, ed. by R. Kukla, 35-60, Cambridge: Cambridge University Press.

Goldberg, N. J. (2015), Kantian Conceptual Geography, Oxford: Oxford University Press.

Gowans, C. W. (1984), “C. I. Lewis's Critique of Foundationalism in Mind and the World-Order," Transactions of the Charles S. Peirce Society 20: 241-52.

Grier, M. (2001), Kant's Doctrine of Transcendental Illusion, Cambridge: Cambridge University Press. 
Heis, J. (2014), "Realism, Functions, and the A Priori: Ernst Cassirer's Philosophy of Science," Studies in History and Philosophy of Science 48: 10-19.

Heßbrüggen-Walter, S. (2004), “Topik, Reflexion und Vorurteilskritik: Kants 'Amphibolie der Reflexionsbegriffe' im Kontext," Archiv für Geschichte der Philosophie, 86: 146-75.

Heney, D. (2017), “C.I. Lewis: From Conceptual Pragmatism to Contemporary Metaethics,” in Pragmatism in Transition: Contemporary Perspectives on C.I. Lewis, ed. by P. Olen and C. Sachs, 35-61, London: Palgrave Macmillan.

Hookway, C. (2012), "Pragmatism and the Given: C. I. Lewis, Quine and Peirce," in The Pragmatic Maxim: Essays on Peirce and Pragmatism, 149-64, Oxford: Oxford University Press.

Kant, I. (1998), Critique of Pure Reason, trans. by P. Guyer and A. Wood, Cambridge: Cambridge University Press.

La Rocca, C. (1999), Esistenza e Giudizio: Linguaggio e ontologia in Kant, Pisa: Edizioni ETS.

Leitner, H. (1994), Systematische Topik: Methode und Argumentation in Kants kritischer Philosophie, Würzburg: Königshausen \& Neumann.

Lewis, C. I. (1929), Mind and the World Order: Outline of a Theory of Knowledge. New York: Charles Scribner's Sons; Reissued with corrections by the author: New York: Dover Publications, 1956.

Lewis, C. I. (1970), Collected Papers of Clarence Irving Lewis, ed. by J. D. Goheen and J. L. Mothershead Jr., Stanford: Stanford University Press.

Limbeck-Lilienau, C. (2012), “Carnap's Encounter with Pragmatism," in Rudolf Carnap and the Legacy of Logical Empiricism, ed. by R. Creath, 89-111, Dordrecht: Springer.

Longuenesse, B. (1998), Kant and the Capacity to Judge, Princeton: Princeton University Press. 
Merritt, M. M. (2015), "Varieties of Reflection in Kant's Logic," British Journal for the History of Philosophy, 23: 478-501.

Misak, C. (2013), The American Pragmatists, Oxford: Oxford University Press.

Mormann, T. (2012), "Toward a Theory of the Pragmatic A Priori: From Carnap to Lewis and Beyond," in Rudolf Carnap and the Legacy of Logical Empiricism, ed. by R. Creath, 113-32, Dordrecht: Springer.

Murphey, M. G. (2005), C. I. Lewis: The Last Great Pragmatist, Albany, NY: SUNY Press.

Olen, P. (2017), "Diverging Paths? Conceptual Pragmatism and Logical Empiricism," in Pragmatism in Transition: Contemporary Perspectives on C.I. Lewis, ed. by P. Olen and C. Sachs, 63-77, London: Palgrave Macmillan.

O'Shea, J. (2006), "Conceptual Connections: Kant and the Twentieth-Century Analytic Tradition," in A Companion to Kant, ed. by G. Bird, 513-26, Oxford: Blackwell.

O’Shea, J. (2016), “Concepts of Objects as Prescribing Laws: A Kantian and Pragmatist Line of Thought," in Pragmatism, Kant and Transcendental Philosophy, ed. by G. Gava and R. Stern, 196216, London: Routledge.

Parkinson, G. H. R. (1981), "Kant as a Critic of Leibniz: The Amphiboly of Concepts of Reflection," Revue internationale de philosophie, 35: 302-14.

Pereboom, D. (1991), “Kant's Amphiboly,” Archiv für Geschichte der Philosophie, 73: 50-70.

Poincaré, H. (1902), La Science et l'Hypothèse, Paris: Flammarion.

Reichenbach, H. (1920), Relativitätstheorie und Erkenntnis apriori, Berlin: Springer.

Richardson, A. (2007), "Carnapian pragmatism," in The Cambridge Companion to Carnap, ed. by M. Friedmann and R. Creath, 295-315, Cambridge: Cambridge University Press. 
Rosenthal, S. (2007), C.I. Lewis in Focus: The Pulse of Pragmatism, Bloomington: Indiana University Press.

Sachs, C. (2014), Intentionality and the Myths of the Given, London: Pickering \& Chatto.

Smit, H. (1999), “The Role of Reflection in Kant's Critique of Pure Reason," Pacific Philosophical Quarterly, 80: 203-23.

Strawson, P. (1959), Individuals: An Essay in Descriptive Metaphysics, London: Methuen.

Strawson, P. (1992), Analysis and Metaphysics: An Introduction to Philosophy, Oxford: Oxford University Press.

Westphal, K. (2010), “Kant's Critique of Pure Reason and Analytic Philosophy,” in The Cambridge Companion to Kant's Critique of Pure Reason, ed. by P. Guyer, 401-30, Cambridge: Cambridge University Press.

Westphal, K. (2017), "Empiricism, Pragmatic Realism, and the A Priori in Mind and the World Order," in Pragmatism in Transition: Contemporary Perspectives on C.I. Lewis, ed. by P. Olen and C. Sachs, 169-98, London: Palgrave Macmillan.

Willaschek, M. (1998), "Phaenomena/Noumena und die Amphibolie der Reflexionsbegriffe," in Immanuel Kant: Kritik der reinen Vernunft, ed. by G. Mohr and M. Willaschek, 325-52, Berlin: Akademie Verlag. 